in vivo $34: 2423-2429(2020)$

doi:10.21873/invivo.12056

\title{
Impact of Deserosalization on Small Bowel Anastomosis Healing in Swine: A Pilot Study
}

\author{
GAVRIELLA-ZOI VRAKOPOULOU ${ }^{1}$, KONSTANTINOS G. TOUTOUZAS ${ }^{1}$, PANAGIOTIS GIANNIOS ${ }^{2}$, \\ SOTIRIOS-GEORGIOS PANOUSOPOULOS ${ }^{1}$, CHARALAMPOS THEODOROPOULOS $^{1}$, EUGENE DANAS $^{3}$, \\ ALIKI LIAKEA ${ }^{3}$, APOSTOLOS E. PAPALOIS $^{4,5}$, GEORGE ZOGRAFOS $^{1}$ and ANDREAS LARENTZAKIS ${ }^{1 *}$ \\ ${ }^{1}$ First Department of Propaedeutic Surgery, Hippocration General Athens Hospital, \\ Athens Medical School, National and Kapodistrian University of Athens, Athens, Greece; \\ ${ }^{2}$ Institute for Research in Biomedicine (IRB Barcelona), \\ The Barcelona Institute of Science and Technology, Barcelona, Spain; \\ ${ }^{3}$ First Department of Pathology, Athens Medical School, \\ National and Kapodistrian University of Athens, Athens, Greece; \\ ${ }^{4}$ Experimental, Educational and Research Center ELPEN, Pikermi, Greece; \\ ${ }^{5}$ School of Medicine, European University Cyprus, Nicosia, Cyprus
}

\begin{abstract}
Background: Healing is related to gastrointestinal anastomotic leak, which is a severe and common complication. This study aimed to investigate the feasibility and the impact of deserosalization on healing of jejuno-jejunal anastomoses in an animal model. Materials and Methods: Seven swine underwent three types of side-to-side jejuno-jejunal anastomosis twice and survived seven days. Three different types of jejuno-jejunal sideto-side anastomoses were performed twice at 20-cm distance from each other in each animal: no serosa removal, one-sided, and two-sided serosa removal, respectively. Bursting pressure, tissue hydroxyproline concentration, and pathology scores were evaluated. Results: Hydroxyproline tissue concentration was a mean \pm standard deviation of $0.37 \pm 0.09,0.38 \pm 0.08$, and $0.30 \pm 0.05 \mathrm{nmol} / \mathrm{ml}$ respectively $(p<0.05)$. Bursting pressure was a mean \pm standard deviation of $59.02 \pm 8.60,73.20 \pm 11.09$, and $100.01 \pm 7.49 \mathrm{mmHg}$, respectively $(p<0.001)$. The histopathological assessment did not find any statistically significant differences. Conclusion: Deserosalization in jejunojejunal anastomosis was technically feasible and seemed to improve mechanical strength and collagen deposition in this experimental porcine model. Further investigation is warranted.
\end{abstract}

This article is freely accessible online.

Correspondence to: Andreas Larentzakis, MD, MSc, Ph.D., FACS, First Department of Propaedeutic Surgery, Hippocration General Athens Hospital, Athens Medical School, National and Kapodistrian University of Athens, 114 Leoforos Vassilissis Sofias, 11527 , Athens, Greece. Mobile: +30 6945917272, Fax: +30 2132089541, e-mail: alarentz@med.uoa.gr

Key Words: Anastomosis, deserosalization, healing, jejunum, technique.
The tissue healing process depends on multiple biological events. Optimum healing remains a significant challenge for general surgeons since anastomotic leakage is a severe complication resulting in increased morbidity and mortality, even when it is performed by experienced surgeons (1-7). However, dependent on the site, anastomotic leakage rates vary significantly according to the existing literature, with esophagogastric and esophagojejunal leakage ranging from $15.9 \%$ to $21.2 \%$ and from $2.1 \%$ to $14.6 \%$, respectively $(8,9)$; gastroenteric and enteroenteric from $1 \%$ to $9 \%$ and from $1 \%$ to $3 \%$, respectively (10); while ileocolic, colonic, and rectal anastomosis leakage rates range between $1 \%$ and $3 \%, 3 \%$ and $29 \%$, and up to $41 \%$, respectively $(4-6,10)$. Usually, diagnosis of leakage occurs during the fifth to seventh postoperative day (POD) $(1,2)$.

The development of new techniques or modifications of old ones and the improvement of surgical devices and pharmacological agents for optimal anastomotic healing has been a significant research topic during the past decades (1116). Towards this end, it is essential to understand the histology, biology, and corresponding mechanical properties of anastomoses during healing.

The gastrointestinal tract consists of four layers: the mucosa, submucosa, muscularis propria, and serosa. The serosa is not present at extraperitoneal structures such as the esophagus or the lower third of the rectum. The mucosal layer consists of an epithelium, the lamina propria, a loose connective tissue containing collagen, and the muscularis mucosa. In 1887 , Halsted et al. demonstrated that the submucosa is mainly responsible for the mechanical properties of the gastrointestinal tract (17). This layer consists of collagen, blood vessels, lymphatics, and nerve fibers. Type I collagen predominates $(68 \%)$, followed by type III $(20 \%)$, and type V $(12 \%)(17,18)$. 
Healing consists of a three-phase process. The initial phase lasts up to 4 days and is characterized by inflammation and accumulation of neutrophils, monocytes, and macrophages (19-22). During the second (proliferative) phase, fibroblasts are responsible for collagen deposition, and collagen-rich tissue gradually replaces the provisional matrix established in the inflammatory phase (21-23). Finally, during the last, remodeling, phase, the collagen fibers are organized into thick bundles, while the percentage of collagen type III is reduced to almost $20 \%$ and that of type I increases $(23,24)$.

Intestinal healing assessment methods include mechanical tests, such as bursting pressure (BP) (24), biochemical ones, such as tissue hydroxyproline concentration, and histopathological findings.

The triggering of the healing process and the resulting development of postoperative adhesions following mechanical injury of the peritoneal surface led to the idea of the use of deserosalization in intestinal anastomoses (25). We hypothesized that deserosalization has a positive impact on anastomotic healing.

In this pilot study, we investigated the feasibility of deserosalization as a novel approach in anastomosis. At the same time, we aimed to assess the impact of deserosalization on the healing process and collagen formation in jejunojejunal anastomoses, through evaluation of $\mathrm{BP}$, tissue hydroxyproline concentration, and pathology.

\section{Materials and Methods}

The Institutional Animal Care and Use Committee and the Veterinary Authorities of East Attica Region (Ref. number 2990) approved experiments described herein, under Greek Law No. 160, A-64, May 1991, which adheres to the Guiding Principles in the Care and Use of Animals approved by the Council of the American Physiological Society and complies with European Union regulations (EU Directive 2010/63/EU), ARRIVE guidelines, and the Guide for the Care and Use of Laboratory Animals (26).

Animal care and preparation. The seven female Landrace swine used had a weight range of $30-32 \mathrm{~kg}$ and were 4-5 months old. Animals were fed with a standard diet and observed for a minimum of 1 week to ensure a good state of health and acclimatization. After 12-hour fasting and ad libitum water access, the animals were prepared for the experimental operation.

Anesthesia and monitoring. All animals were initially sedated by intramuscular injection of ketamine hydrochloride $(10 \mathrm{mg} / \mathrm{kg})$, midazolam $(0.5 \mathrm{mg} / \mathrm{kg})$, and atropine $(0.05 \mathrm{mg} / \mathrm{kg})$. Subsequently, they were transferred to the operating table, induced to anesthesia with an $i . v$. bolus propofol $(2 \mathrm{mg} / \mathrm{kg})$ dose via the marginal auricular vein, and intubated with a cuffed endotracheal tube (4.0-5.0 $\mathrm{mm}$ ). A volume-controlled ventilator (AM 5000 Major International, Alpha Delta Ventilator; SIARE, Bologna, Italy) was used with initial settings of $15 \mathrm{ml} / \mathrm{kg}$ tidal volume, 14 breaths/min, and $60 \%$ oxygen. The settings were adjusted to maintain normoxia and normocapnia. Continuous infusion of $2 \%$ propofol at $150 \mu \mathrm{g} / \mathrm{kg} / \mathrm{min}$ and fentanyl citrate at $50 \mu \mathrm{g} / \mathrm{kg} / \mathrm{h}$ maintained adequate anesthetic depth and analgesia. A bolus dose of cisatracurium $(0.15 \mathrm{mg} / \mathrm{kg})$ was repeated as needed. Vital signs monitoring was continuous. An i.v. dose of $750 \mathrm{mg}$ cefuroxime was administered.

Surgery. Surgery was performed under aseptic and antiseptic techniques. The abdominal cavity was accessed via a $15 \mathrm{~cm}$ midline incision. During the abdominal exploration, the stomach, duodenum, and proximal jejunum were identified. Subsequently, $20 \mathrm{~cm}$ distally to the duodenum, three different types of jejuno-jejunal side-to-side anastomoses were performed twice at 20 -cm distance from each other. Thus, each animal received six anastomoses in total. The three types of anastomoses were the following: A: No removal of the serosal layer (serosa-serosa), B: the serosal layer was removed only from the proximal jejunal helix before the anastomosis (serosa-subserosa), and C: the jejunal serosaI layer was removed from both the proximal and distal jejunal helices before the anastomosis (subserosa-subserosa). The type order (proximally to distally) of the six anastomoses per animal was defined according to the following rules: a) The three most proximal anastomoses were allocated to include all the possible permutations for the three types at least once; the permutation to be represented twice was randomly selected; b) the three most distal anastomoses were allocated to include all possible permutations for the three types at least once; the permutation represented twice was randomly selected; c) the combination of rules "a" and "b" to create the final order was random. The data regarding the order of types of anastomoses per animal were recorded.

The jejunal area of deserosalization had an elliptical shape with a 4 $\mathrm{cm}$-wide major axis along the jejunal antimesenteric border and a 2$\mathrm{cm}$-wide minor axis (Figure 1A and B). A side-to-side jejuno-jejunal two-layer anastomosis was fashioned using 5-0 absorbable monofilament sutures (polydioxanone, PDS II; Ethicon Inc., Johnson \& Johnson Medical Devices Companies, Somerville, NJ, USA). Interrupted sutures were used for the outer layer, and continuous suturing was used for the inner layer of the anastomosis. The external sutures of the dorsal anastomosis aspect were placed along the edge of the deserosalized area before the jejunal lumens of both the helices were opened (Figure 1C). Then a continuous inner suture was fashioned incorporating the submucosa and the muscle layer, in a $5 \mathrm{~mm}$ thickness and $5 \mathrm{~mm}$ step. Finally, outer sutures of the ventral anastomosis aspect were placed along the edge of the deserosalized area once again. The abdominal wall was closed with a single-layer of nylon 2-0 suturing. The skin was approximated with interrupted stitches.

Postoperative period. A liquid diet was resumed $6 \mathrm{~h}$ postoperatively, and was advanced to a free one at POD 2. On POD 2, blood samples were obtained for white blood cell count, C-reactive protein, albumin, and total protein levels. On POD 7, animals underwent explorative laparotomy. The abdomen was examined for any macroscopic evidence of a leak. Following the in vivo BP measurement, each anastomotic segment was resected en bloc and divided into two symmetrical parts on the antimesenteric plane. One part was fixed in $10 \%$ formaldehyde solution, and one was preserved in liquid nitrogen. Terminal procedures were performed under general anesthesia.

Bursting pressure measurements. The resistance of the intestinal wall to increasing intraluminal pressure until the disruption of the anastomotic line is defined as BP and can be measured in vivo or in vitro (24). In our study, the bowel was in vivo externally obstructed 3 


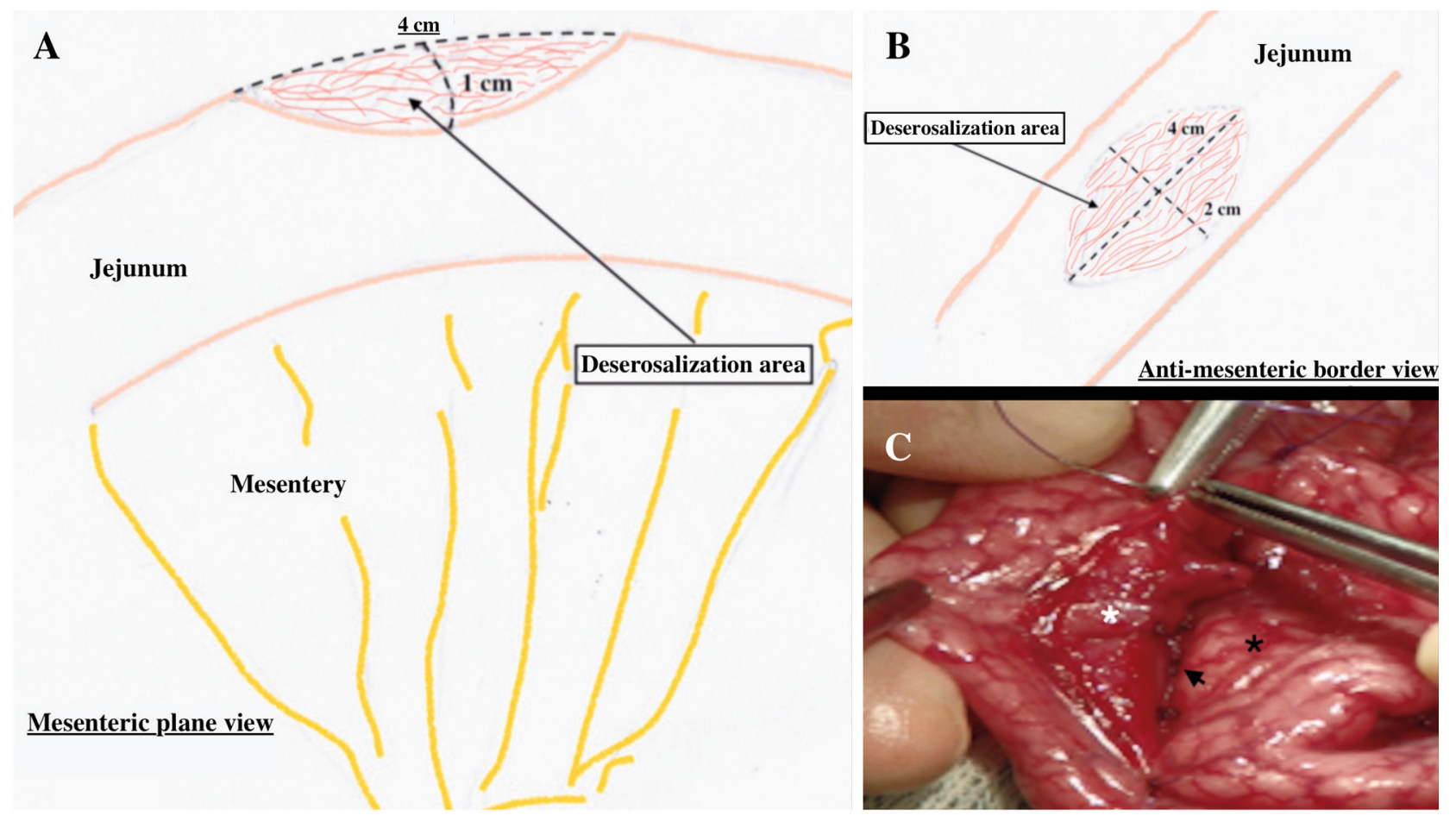

Figure 1. Presentation of the deserosalization technique. A and B: Schematic presentation of the place and size of the deserosalization area for each jejunal helix. C: In type B anastomosis, the serosal layer from only one side of the jejunal helix was removed. The black asterisk indicates the serosal surface; the white asterisk indicates the subserosa area; the arrowhead indicates the external sutures of the dorsal aspect of the anastomosis, which were placed along the edge of the deserosalized area before the jejunal lumen opening.

$\mathrm{cm}$ above and below the anastomosis using 2 Overholdt clamps. Two 14-Fr catheters were inserted into the jejunal lumen and secured on the proximal and distal end of the anastomosis. The proximal catheter was used for the infusion of diluted water-soluble iodinated radiopaque contrast (Gastrografin; Bayer Hellas Commercial \& Industrial S.A., Marousi, Athens, Greece) at a rate of $3 \mathrm{ml} / \mathrm{min}$, under continuous videofluoroscopy. The distal catheter was used for pressure monitoring. The pressure at which contrast liquid was detected outside the enteral lumen was recorded as the anastomosis BP.

Tissue hydroxyproline concentration. Hydroxyproline is almost unique to collagen. Up to $14 \%$ of dry collagen weight is composed of hydroxyproline (27). Thus, the tissue concentration of hydroxyproline is used as an estimate of collagen content. Anastomotic tissue levels of hydroxyproline in the 42 liquid nitrogen-preserved samples were measured using an enzyme-linked immunosorbent assay (ELISA) kit (BG HYP ELISA Kit; BlueGene Biotech Co., Ltd., Shanghai, China). Cubic tissue specimens $(0.5 \times 0.5 \times 0.5 \mathrm{~cm})$ were excised from the anastomotic site, rinsed in ice-cold phosphate-buffered saline (pH 7.2; PBS), and weighed. The tissues were minced and homogenized in $0.5 \mathrm{ml}$ PBS with a glass homogenizer on ice. The suspension was subjected to two freezethaw cycles, and the homogenates were centrifuged at 2,000 $\times g$ for $15 \mathrm{~min}$. The total protein content of the supernatants was determined following Bradford's assay, while aliquoted samples kept at $-80^{\circ} \mathrm{C}$ until analysis. The ELISAs were performed in triplicates, as per the manufacturer's instructions (limit of quantification $=0.003 \mathrm{nmol} / \mathrm{ml}$, limit of detection $=0.001 \mathrm{nmol} / \mathrm{ml})$.
Histological evaluation. Five micrometer-thick sections were prepared for histological examination after dehydration and paraffin embedding. Sections were stained with hematoxylin-eosin stain (HES) and Masson's trichrome stain (MTS) and evaluated under a light microscope (Eclipse E200; Nikon Corporation, Tokyo, Japan) by two pathologists. The HES colors cell nucleus blue and other eosinophilic structures in various shades of red, pink, and orange. MTS colors collagen as blue or green, cytoplasm as red, and nuclei as black.

We used a modified scoring system (28) as a semi-quantitative method for the histological assessment. It included four parameters of acute inflammation (i.e. polymorphonuclear neutrophil infiltrate, edema, hemorrhage, and necrosis), as for the calculation of the total histological acute inflammation score (HAIS), and three parameters of tissue repair (i.e. fibroblast proliferation, collagen density, and neovascularization), as for the calculation of the histological repair score (HRS). The above-mentioned parameters were assessed using the following scoring system for each one: 0 , None present/minimal; 1 , mild; 2 , moderate; 3 , marked. The interpretation of collagen density was based on the intensity and depth of distribution within tissue sections according to the following scoring values: 0 , none; 1 , superficial; 2, superficial to mid-layers; 3, all layers. The HAIS (range $=0-12$ ) and HRS (range $=0-9$ ) were calculated for each specimen.

Statistical analysis. Statistical analysis was conducted either with the Statistical Package for the Social Sciences (SPSS, version 23.0; IBM, Armonk, NY, USA) or with GraphPad Prism v. 7 for Macintosh (GraphPad Software, San Diego, CA, USA). For normally distributed data, t-test or one-way ANOVA was used. The 
Table I. Tissue hydroxyproline concentration for each type of anastomosis. Values are the mean \pm standard deviation.

\begin{tabular}{lc}
\hline Type of anastomosis & Hydroxyproline concentration $(\mathrm{nmol} / \mathrm{ml})^{*}$ \\
\hline A: Serosa-serosa & $0.30 \pm 0.05^{* *}$ \\
B: Serosa-subserosa & $0.37 \pm 0.09^{* *}$ \\
C: Subserosa-subserosa & $0.38 \pm 0.08^{* *}$ \\
\hline
\end{tabular}

*One-way ANOVA analysis, hydroxyproline change across types: $p<0.05$. **Tukey's post-hoc test, Type A vs. C: $p<0.01$, there were no other statistically significant differences.

non-parametric alternatives Mann-Whitney $U$-test and KruskalWallis test were performed when assumptions underlying parametric tests were violated. For all statistical analyses, a $p$-value of less than 0.05 was considered significant.

\section{Results}

Macroscopic in vivo assessment. None of the animals demonstrated any macroscopic evidence of leakage during explorative laparotomy on POD 7.

Bursting pressure. Type A, B and C anastomoses exhibited a mean \pm standard deviation $\mathrm{BP}$ of $59.02 \pm 8.60 \mathrm{mmHg}$, $73.20 \pm 11.09$ and $100.01 \pm 7.49 \mathrm{mmHg}$, respectively, with a statistically significant change across types $(p<0.001)$.

Hydroxyproline. Table I shows the tissue hydroxyproline concentration for each type, indicating increased collagen synthesis and deposition in type $\mathrm{C}$ anastomosis. Fluctuations in hydroxyproline concentration among the animals may add variability to the measured values. Thus, we calculated the difference between the mean values by subtracting the mean for type A samples from those of type $\mathrm{C}$ for each animal (Figure 2), which also indicated increased collagen deposition in type $\mathrm{C}$ anastomoses compared to A intra-individually.

Gross and histological evaluation of the anastomotic sites. On gross visual inspection, all the animals demonstrated excellent healing of the jejuno-jejunal anastomosis. HES and MTS sections revealed good layer apposition without any microscopic discontinuity throughout the anastomotic site (Figures 3 and 4). The HRS and HAIS are shown in Table II. Among types of anastomoses, there was no statistically significant difference regarding HAIS or its subparts (i.e., neutrophilic cellular infiltration, degree of edema, hemorrhage, and necrosis). The hemorrhage score was zero for all the samples of all types. Likewise, between-type comparisons in terms of HRS or its parts (i.e. fibroblast proliferation, collagen density, and neovascularization) did not reach any statistical significance.

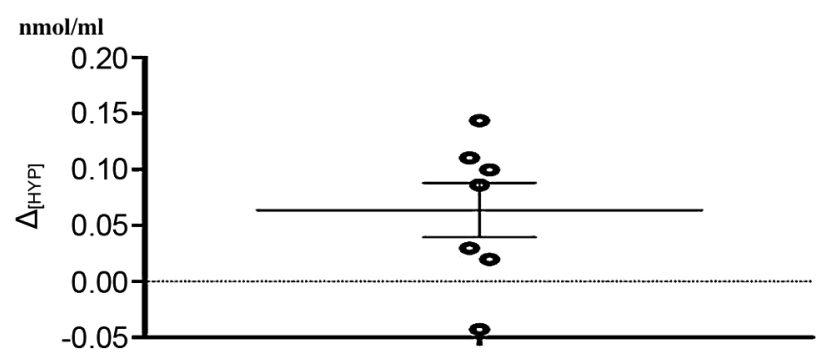

Figure 2. Comparison of hydroxyproline concentration [HYP] between type $C$ and $A$ anastomoses intra-individually. The scattered dot plot presents the difference in the mean hydroxyproline concentration $(\triangle[H Y P])$ between type $C$ and $A$ anastomoses for each animal (intraindividually), according to the following formula: $\triangle[H Y P]=$ mean $\left[H Y P_{C}\right]$ - mean $\left[H Y P_{A}\right]$, where mean $\left[H Y P_{C}\right]$ and mean $\left[H Y P_{A}\right]$ represent the mean hydroxyproline concentration of the two type $C$ and two type $A$ anastomoses, respectively, for each animal. Horizontal line and error bars data are the mean $\triangle[H Y P]$ values \pm standard error of the mean $(p=0.0496)$.

\section{Discussion}

Anastomotic healing remains a significant challenge for all surgeons of the gastrointestinal tract, with a high impact on patient outcomes. Despite improvements in the management of nutritional status (29), pre- and postoperative glycemic control (30), tension-free anastomotic techniques (31), and a revered number of other related to anastomosis healing variables, the leakage rate still ranges from $2 \%$ to $7 \%$, even when performed by experienced surgeons $(1-3,32)$. Several animal studies have provided crucial information on a variety of anastomosis techniques; however, a systematic review on the subject revealed that the actual translational value to clinical practice seems to be very limited (33).

The idea that deserosalization might affect healing has been reported (34). According to the present pilot study, the deserosalization technique was feasible through a 4-cm-long incision of the serosal layer along the jejunal antimesenteric axis using a scalpel. This incision caused minimum damage to the underlying longitudinal muscle layer, with minimal, if any, bleeding, which did not need hemostasis. The next step was to bluntly detach the serosa from the underlying longitudinal muscle layer about $1 \mathrm{~cm}$ in the bilateral direction to create the elliptical deserosalized area. The serosal flaps developed were subsequently excised using scissors. There was no visible evidence of damage to the underlying muscle layers. Bleeding was minimal and required no hemostasis. The amount of time needed to create each deserosalized elliptical $(4 \times 2 \mathrm{~cm})$ area was between 2 and $3 \mathrm{~min}$.

A plethora of these studies provides us with useful data about the criteria for evaluation of anastomotic healing and strength. Taking into account that the submucosa (17) and the final balance between collagen breakdown and synthesis are mainly responsible for many mechanical properties of the 

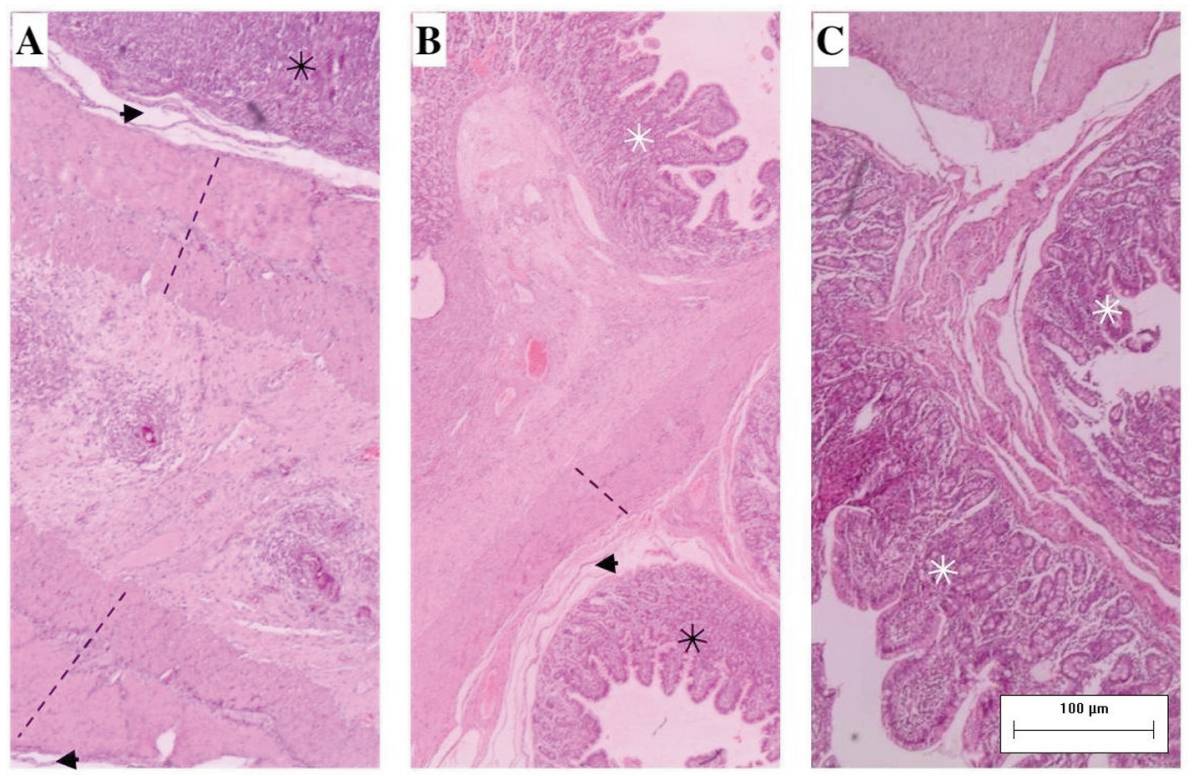

Figure 3. Hematoxylin and eosin-stained sections of type $A, B$, and $C$ jejuno-jejunal anastomoses ( $A$-C, respectively). Black asterisks indicate the mucosa of the jejunal loop from which the serosa was not removed; white asterisks indicate the mucosa of the jejunal loop from which the serosa was removed; dotted lines indicate the muscularis propria of the jejunal loop that the serosa was not removed; arrowheads indicate the submucosa of the jejunal loop from which the serosa was not removed.

Table II. Results of pathology assessment for the different types of anastomoses.

\begin{tabular}{lcccc}
\hline & $\begin{array}{r}\text { Histological } \\
\text { repair score }\end{array}$ & $\begin{array}{c}\text { Histological assessment } \\
\text { inflammation score }\end{array}$ \\
\cline { 2 - 5 } Type of anastomosis & Mean \pm SD & Median & Mean \pm SD & Median \\
\hline A: Serosa-serosa & $2.43 \pm 1.55$ & 2.00 & $3.71 \pm 1.14$ & 4.00 \\
B: Serosa-subserosa & $4.00 \pm 2.04$ & 3.50 & $4.35 \pm 1.82$ & 4.00 \\
C: Subserosa-subserosa & $3.36 \pm 1.39$ & 3.50 & $3.35 \pm 1.15$ & 3.50 \\
\hline
\end{tabular}

SD: Standard deviation. Kruskal-Wallis test/one-way ANOVA between types revealed differences to be non-significant.

anastomosis (35), we conducted our study to verify if a simple modification, namely deserosalization, of a wellknown anastomotic technique affected healing. As a result of the healing process, anastomotic strength requires a multifactorial analysis of different parameters. In our study, we used BP, histopathological tissue analysis, and collagen content estimation through measurement of tissue hydroxyproline concentration (36).

Our statistically significant data demonstrate that the deserosalization of one or both sides of the anastomotic surface resulted in higher BP and tissue hydroxyproline values. Thus, they suggest a positive impact of deserosalization on tissue
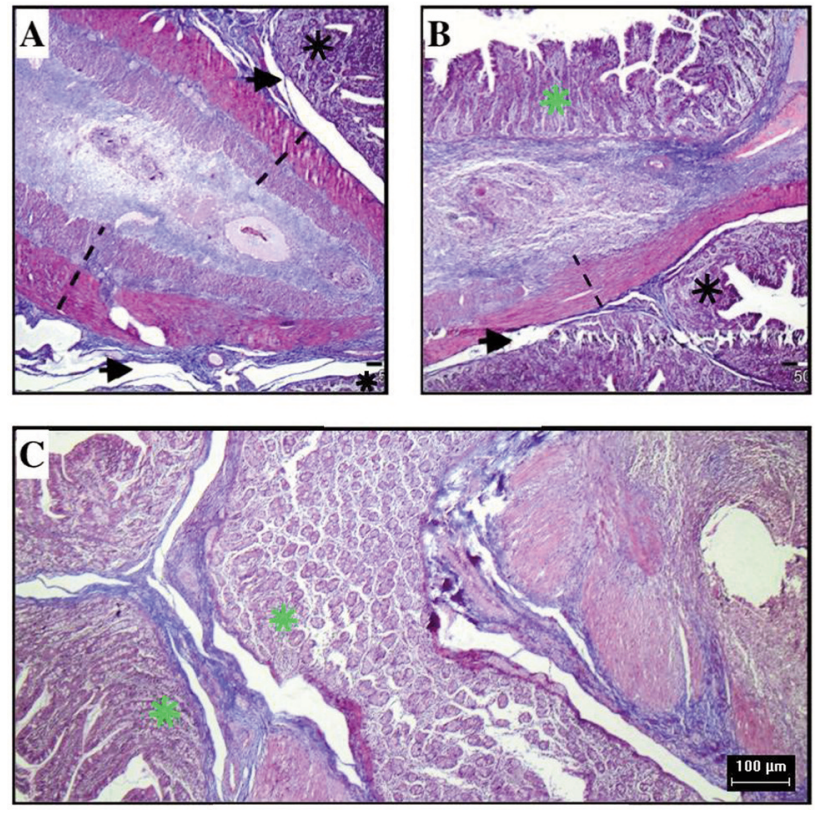

Figure 4. Masson's trichrome-stained sections of type A, B, and $C$ jejuno-jejunal anastomoses ( $A-C$, respectively). Black asterisks indicate the mucosa of the jejunal loop from which the serosa was not removed; green asterisks indicate the mucosa of the jejunal loop from which the serosa was removed; dotted lines indicate the muscularis propria of the jejunal loop from which the serosa was not removed; arrowheads indicate the submucosa of the jejunal loop from which the serosa was not removed. 
strength and collagen deposition, respectively. In the same way, they suggest more increased collagen synthesis and deposition in type $\mathrm{C}$, in which the serosa layer was removed from both sides of jejunal helices, compared with type A in which there was no serosa removal. Consistent with the results of the interindividual analysis, the increased collagen deposition in type $\mathrm{C}$ anastomoses compared to type A samples was also confirmed intra-individually. However, it cannot be assumed that there is an etiological relation between deserosalization on the one hand, and increased collagen deposition or tissue strength on the other. Our supporting theory that needs to be tested is that the deserosalization of at least one anastomotic surface creates minimum mechanical injury that further enhances healing.

Pathology data did not show any statistically significant difference among anastomotic surfaces, whether deserosalized or not. Histopathology scores are usually less reliable due to the method's subjectivity, as it is a semiquantitative one, which is one of the limitations of this study. Another is the small number of animals used. Moreover, the lack of leakage, as well as the fact that the study design did not account for other possible leakage factors, add to the limitations of this study.

In conclusion, this study demonstrated that deserosalization was easy to perform and was not a time-consuming procedure. This technique seems to add to increased mechanical strength and collagen deposition of the jejuo-jejunal anastomosis. This innovative, modified anastomotic technique possibly deserves to be further investigated.

\section{Conflicts of Interest}

None of the Authors have commercial interest, financial or relevant financial relationships or any other conflict of interest, as it pertains to the content of this article.

\section{Authors' Contributions}

All the Authors have made substantial contributions to: a) the conception and design of the study, or acquisition of data, or analysis and interpretation of data and b) drafting the article or revising it critically for important intellectual content.

In detail, GZV contributed to the design of the study, performed the experiments, interpreted the data, and co-wrote the article; KGT contributed to the conception and design of the experiment, and critically revised the article; PG performed laboratory tests, analyzed and interpreted the data, and co-wrote the article; SGP performed the experiments and critically revised the article; CT analyzed and interpreted the data and critically revised the article; ED performed pathology assessments, analyzed and interpreted the data, and critically revised the article; A Liakea performed pathology assessments, analyzed and interpreted the data, and critically revised the article; AP contributed to the conception and design of the study and critically revised the article; GZ contributed to the conception and design of the study and critically revised the article; A Larentzakis contributed conception and design of the study, performed the experiments, and critically revised the article. All Authors are in agreement with the content of the article and gave their final approval of the version to be submitted.

\section{Acknowledgements}

This study was supported as a scholarship provided by the Experimental, Educational and Research Center, ELPEN. The Authors would like to thank Professor Karathanos and A. Katsarou for their help. Finally, the Authors would like to dedicate this work to the memory of Professor S. Katsaragakis for his contribution to the conception of the study.

\section{References}

1 Hyman N, Manchester TL, Osler T, Burns B and Cataldo PA: Anastomotic leaks after intestinal anastomosis: It's later than you think. Ann Surg 245(2): 254-258, 2007. PMID: 17245179. DOI: 10.1097/01.sla.0000225083.27182.85

2 Kingham TP and Pachter HL: Colonic anastomotic leak: Risk factors, diagnosis, and treatment. J Am Coll Surg 208(2): 269-278, 2009. PMID: 19228539. DOI: 10.1016/j.jamcollsurg.2008.10.015

3 Park JS, Choi GS, Kim SH, Kim HR, Kim NK, Lee KY, Kang SB, Kim JY, Lee KY, Kim BC, Bae BN, Son GM, Lee SI and Kang $\mathrm{H}$ : Multicenter analysis of risk factors for anastomotic leakage after laparoscopic rectal cancer excision: The Korean Laparoscopic Colorectal Surgery Study Group. Ann Surg 257(4): 665-671, 2013. PMID: 23333881. DOI: 10.1097/SLA.0b013e31827b8ed9

4 Buchs NC, Gervaz P, Secic M, Bucher P, Mugnier-Konrad B and Morel P: Incidence, consequences, and risk factors for anastomotic dehiscence after colorectal surgery: A prospective monocentric study. Int J Colorectal Dis 23(3): 265-270, 2008. PMID: 18034250. DOI: 10.1007/s00384-007-0399-3

5 Kube R, Mroczkowski P, Granowski D, Benedix F, Sahm M, Schmidt U, Gastinger I, Lippert $\mathrm{H}$ and Study group Qualitatssicherung Kolon/Rektum-Karzinome (Primärtumor) (Quality assurance in primary colorectal carcinoma): Anastomotic leakage after colon cancer surgery: A predictor of significant morbidity and hospital mortality, and diminished tumour-free survival. Eur J Surg Oncol 36(2): 120-124, 2010. PMID: 19775850. DOI: 10.1016/j.ejso.2009.08.011

6 Ptok H, Marusch F, Meyer F, Schubert D, Gastinger I, Lippert $\mathrm{H}$ and Study Group Colon/Rectum Carcinoma (Primary Tumour): Impact of anastomotic leakage on oncological outcome after rectal cancer resection. Br J Surg 94(12): 1548-1554, 2007. PMID: 17668888. DOI: 10.1002/bjs.5707

7 Rutegard M, Lagergren P, Rouvelas I and Lagergren J: Intrathoracic anastomotic leakage and mortality after esophageal cancer resection: A population-based study. Ann Surg Oncol 19(1): 99-103, 2012. PMID: 21769467. DOI: 10.1245/s10434-011-1926-6

8 Baltin C, Kron F, Urbanski A, Zander T, Kron A, Berlth F, Kleinert R, Hallek M, Hoelscher AH and Chon SH: The economic burden of endoscopic treatment for anastomotic leaks following oncological Ivor Lewis esophagectomy. PLoS One 14(8): e0221406, 2019. PMID: 31461487. DOI: 10.1371/journal.pone.0221406

9 Makuuchi R, Irino T, Tanizawa Y, Bando E, Kawamura T and Terashima M: Esophagojejunal anastomotic leakage following gastrectomy for gastric cancer. Surg Today 49(3): 187-196, 2019. PMID: 30317492 . DOI: 10.1007/s00595-018-1726-8 
10 Li C, Zhao Y, Han Z and Zhou Y: Anastomotic leaks following gastrointestinal surgery: Updates on diagnosis and interventions. Int J Clin Exp Med 9(3): 7031-7040, 2016.

11 Bhangu A, Singh P, Fitzgerald JE, Slesser A and Tekkis P: Postoperative nonsteroidal anti-inflammatory drugs and risk of anastomotic leak: Meta-analysis of clinical and experimental studies. World J Surg 38(9): 2247-2257, 2014. PMID: 24682313. DOI: $10.1007 / \mathrm{s} 00268-014-2531-1$

12 He X, Chen Z, Huang J, Lian L, Rouniyar S, Wu X and Lan P: Stapled side-to-side anastomosis might be better than handsewn end-to-end anastomosis in ileocolic resection for Crohn's disease: A meta-analysis. Dig Dis Sci 59(7): 1544-1551, 2014. PMID: 24500450. DOI: 10.1007/s10620-014-3039-0

13 Mazaki T, Ishii Y and Murai I: Immunoenhancing enteral and parenteral nutrition for gastrointestinal surgery: A multipletreatments meta-analysis. Ann Surg 261(4): 662-669, 2015. PMID: 25405556. DOI: 10.1097/SLA.0000000000000935

14 Oines MN, Krarup PM, Jorgensen LN and Agren MS: Pharmacological interventions for improved colonic anastomotic healing: A meta-analysis. World J Gastroenterol 20(35): 1263712648, 2014. PMID: 25253969. DOI: 10.3748/wjg.v20.i35.12637

15 Singh PP, Zeng IS, Srinivasa S, Lemanu DP, Connolly AB and Hill AG: Systematic review and meta-analysis of use of serum C-reactive protein levels to predict anastomotic leak after colorectal surgery. Br J Surg 101(4): 339-346, 2014. PMID: 24311257. DOI: $10.1002 /$ bjs. 9354

16 Wang LH, Fang F, Lu CM, Wang DR, Li P and Fu P: Safety of fast-track rehabilitation after gastrointestinal surgery: Systematic review and meta-analysis. World J Gastroenterol 20(41): 1542315439, 2014. PMID: 25386092. DOI: 10.3748/wjg.v20.i41.15423

17 Thornton FJ and Barbul A: Healing in the gastrointestinal tract. Surg Clin North Am 77(3): 549-573, 1997. PMID: 9194880. DOI: $10.1016 / \mathrm{s} 0039-6109(05) 70568-5$

18 Mast BA: Healing in other tissues. Surg Clin North Am 77(3): 529-547, 1997. PMID: 9194879. DOI: 10.1016/s00396109(05)70567-3

19 Knighton DR, Hunt TK, Scheuenstuhl H, Halliday BJ, Werb Z and Banda MJ: Oxygen tension regulates the expression of angiogenesis factor by macrophages. Science 221(4617): 12831285, 1983. PMID: 6612342. DOI: 10.1126/science.6612342

20 Robson MC, Steed DL and Franz MG: Wound healing: Biologic features and approaches to maximize healing trajectories. Curr Probl Surg 38(2): 72-140, 2001. PMID: 11452260. DOI: $10.1067 / \mathrm{msg} .2001 .111167$

21 Rothe MJ and Falanga V: Growth factors and wound healing. Clin Dermatol 9(4): 553-559, 1991. PMID: 1822411. DOI: 10.1016/0738-081x(91)90084-x

22 Witte MB and Barbul A: General principles of wound healing. Surg Clin North Am 77(3): 509-528, 1997. PMID: 9194878. DOI: 10.1016/s0039-6109(05)70566-1

23 Halloran CM and Slavin JP: Pathophysiology of wound healing. Surgery (Oxf) 20(5): i-v, 2002. DOI: 10.1383/surg.20.5.0.14629

24 Thompson SK, Chang EY and Jobe BA: Clinical review: Healing in gastrointestinal anastomoses, part I. Microsurgery 26(3): 131136, 2006. PMID: 16518804. DOI: 10.1002/micr.20197

25 Arung W, Meurisse M and Detry O: Pathophysiology and prevention of postoperative peritoneal adhesions. World J Gastroenterol 17(41): 4545-4553, 2011. PMID: 22147959. DOI: 10.3748/wjg.v17.i41.4545
26 Institute of Laboratory Animal Resources (U.S.), Netlibrary Inc. Guide for the Care and Use of Laboratory Animals. Seventh Edition. National Academy Press: Washington, DC, 1996.

27 Avery NC, Sims TJ, Warkup C and Bailey AJ: Collagen crosslinking in porcine m. Longissimus lumborum: Absence of a relationship with variation in texture at pork weight. Meat Sci 42(3): 355-369, 1996. PMID: 22060782. DOI: 10.1016/03091740(95)00021-6

28 Yeh DD, Nazarian RM, Demetri L, Mesar T, Dijkink S, Larentzakis A, Velmahos G and Sadik KW: Histopathological assessment of oasis ultra on critical-sized wound healing: A pilot study. J Cutan Pathol 44(6): 523-529, 2017. PMID: 28256051. DOI: $10.1111 /$ cup. 12925

29 Suding P, Jensen E, Abramson MA, Itani K and Wilson SE: Definitive risk factors for anastomotic leaks in elective open colorectal resection. Arch Surg 143(9): 907-911; discussion 911912, 2008. PMID: 18794430. DOI: 10.1001/archsurg.143.9.907

30 Okamura A, Watanabe M, Imamura Y, Kamiya S, Yamashita K, Kurogochi $\mathrm{T}$ and Mine $\mathrm{S}$ : Preoperative glycosylated hemoglobin levels predict anastomotic leak after esophagectomy with cervical esophagogastric anastomosis. World J Surg 41(1): 200-207, 2017. PMID: 27730354. DOI: $10.1007 / \mathrm{s} 00268-016-3763-\mathrm{z}$

31 Laukötter MG and Senninger N: Anastomosentechniken am gastrointestinaitrakt. Der Chirurg 84(12): 1085-1098, 2013. PMID: 24337221. DOI: 10.1007/s00104-012-2392-9

32 Slieker JC, Komen N, Mannaerts GH, Karsten TM, Willemsen P, Murawska M, Jeekel J and Lange JF: Long-term and perioperative corticosteroids in anastomotic leakage: A prospective study of 259 left-sided colorectal anastomoses. Arch Surg 147(5): 447-452, 2012. PMID: 22249852. DOI: 10.1001/ archsurg.2011.1690

33 Yauw ST, Wever KE, Hoesseini A, Ritskes-Hoitinga M and van Goor H: Systematic review of experimental studies on intestinal anastomosis. Br J Surg 102(7): 726-734, 2015. PMID: 25846745. DOI: $10.1002 /$ bjs. 9776

34 Katsaragakis S, Larentzakis A, Panousopoulos SG, Toutouzas KG, Theodorou D, Stergiopoulos S and Androulakis G: A new pancreaticojejunostomy technique: A battle against postoperative pancreatic fistula. World J Gastroenterol 19(27): 4351-4355, 2013. PMID: 23885146. DOI: 10.3748/wjg.v19.i27.4351

35 Bassi C, Falconi M, Molinari E, Salvia R, Butturini G, Sartori $\mathrm{N}$, Mantovani W and Pederzoli P: Reconstruction by pancreaticojejunostomy versus pancreaticogastrostomy following pancreatectomy: Results of a comparative study. Ann Surg 242(6): 767-771, discussion 771-773, 2005. PMID: 16327486. DOI: 10.1097/01.sla.0000189124.47589.6d

36 Foschi D, Corsi F, Cellerino P, Cassini P and Trabucchi E: Diabetes impairs the development of early strength, but not the accumulation, of collagen during intestinal anastomotic healing in the rat. Br J Surg 82(3): 423-424, 1995. PMID: 7796039. DOI: $10.1002 /$ bjs. 1800820355 